\title{
VARIAÇÕES LINGUÍSTICAS NO PROCESSO DE ENSINO-APRENDIZAGEM DA LÍNGUA ESPANHOLA NA FRONTEIRA BRASIL-BOLÍVIA
}

\author{
Silvilene Brito Melo ${ }^{1}$
}

Sandra Aparecida Fernandes Lopes Ferrari ${ }^{2}$

\section{Resumo}

Esta investigação, em desenvolvimento, está vinculada ao programa de Pós-Graduação em Educação Profissional e Tecnológica do Instituto Federal de Rondônia, insere-se no campo de ensino e aprendizagem de língua estrangeira e tem como objetivo analisar as variações linguísticas da língua espanhola na cidade de Guajará-Mirim - fronteira do Brasil com a Bolívia e suas implicações para o ensino e aprendizagem de espanhol como segunda língua na região. Pretendemos possibilitar aos alunos o conhecimento da diversidade linguística do espanhol, visando a valorização da variação linguística presente na região. O estudo busca contribuir com o processo de ensino aprendizagem, promovendo a motivação e interação dos alunos estudantes da língua espanhola na região da fronteira.

Palavras-chave: Formação integral; Ensino-aprendizagem de Espanhol; Variação linguística.

\begin{abstract}
This research, under development, is linked to the Graduate Program in Vocational and Technological Education of the Federal Institute of Rondônia, is part of the field of foreign language teaching and learning and aims to analyze the linguistic variations of the Spanish language in the city of Guajará-Mirim - Brazil's border with Bolivia and its implications for the teaching and learning of Spanish as a second language in the region.
\end{abstract}

\footnotetext{
1 Professora EBTT do IFRO Guajará-Mirim. Mestranda do Programa de Pós-Graduação Mestrado Profissional em Educação Profissional e Tecnológica em Rede Nacional (ProfEPT) - IFRO/Campus Porto Velho Calama. silvilene.melo@ifro.edu.br

2 Doutora em Teoria da Literatura. Docente do programa ProfEPT do IFRO - Campus Calama, sandra@ifro.edu.br
} 
We intend to enable students to know the linguistic diversity of Spanish, aiming at valuing the linguistic variation present in the region. The study seeks to contribute to the teachinglearning process, promoting the motivation and interaction of Spanish language students in the border region.

Keywords: Integral formation; Spanish teaching and learning; Linguistic variation.

\section{INTRODUÇÃO}

Uma das características do território brasileiro é o fato de possuir uma vasta zona de fronteira com países de Língua Castellana. De um modo geral, as fronteiras se caracterizam por serem regiões que apresentam uma flexibilidade sociolinguística, onde atuam duas ou mais línguas. Essa interação se produz pelos falantes das línguas e influência dos meios de comunicação, em particular o rádio e a televisão de ambas as cidades.

As línguas se alternam e os falantes, com versatilidade, utilizam os códigos presentes na fronteira com objetivos comunicativos e identitários. É muito presente, também, a mescla linguística e de empréstimos entre as línguas vizinhas. Estes fenômenos, entretanto, não são generalizados, apresentando uma configuração diferente em cada uma das fronteiras. Na fronteira entre a cidade boliviana Guayaramerín e a cidade brasileira Guajará-Mirim, por exemplo, o ecossistema linguístico é formado por imigrantes europeus, migrantes nordestinos, imigrantes bolivianos, remanescentes de quilombos do Vale do Guaporé, populações indígenas e outros, constituindo uma pluralidade cultural e linguística, onde essa alternância entre as duas línguas português/espanhol não é tão presente, são poucos os falantes que têm domínio dos dois idiomas.

O estado de Rondônia, situado na região Norte do país, também faz parte dessa gama de cidades brasileiras de região fronteiriça. O município de Guajará-Mirim é o segundo maior do Estado em extensão territorial e o oitavo em população. Ele faz fronteira com a cidade boliviana Guayaramerín pertencente ao Departamento de Beni. As cidades gêmeas são separadas geograficamente pelo rio Mamoré, que é também a via de acesso entre as duas cidades. 
Apesar de ser um obstáculo natural, o rio não impede o constante contato social entre os povos dessa região, uma vez que os serviços de lanchas fazem a travessia constante tanto de bolivianos para o lado brasileiro, quanto de brasileiros para o lado boliviano, por uma taxa de embarque que custa, atualmente, o valor de $\mathrm{R} \$ 8,00$ (oito reais). Esse contato constante promove uma interação entre os povos da região e a necessidade de desenvolvimento de habilidades dentro dos idiomas falados por ambos, uma vez que desenvolvem relações comerciais constantes. São inúmeros brasileiros e bolivianos que fazem a travessia todos os dias, principalmente para realizarem compras nos comércios vizinhos.

É grande a busca de cursos de idiomas tanto por brasileiros que desejam aprender o espanhol, como de bolivianos que desejam aprender o português. Pois, ao contrário do que ocorre em outras regiões fronteiriças brasileiras, onde ambas as cidades costumam ter fluência no idioma vizinho, em Guajará-Mirim e Guayaramerín, esta não é uma realidade. Observa-se que o português tem uma presença bem mais marcante em Guayaramerín do que o Espanhol em Guajará-Mirim. Muitos alunos bolivianos estudam em escolas na cidade brasileira e, da mesma forma, muitos alunos brasileiros estudam na cidade boliviana, principalmente os que buscam os preços acessíveis dos cursos de medicina na Bolívia. Esse contexto intercultural torna o conhecimento e uso das variações linguísticas do espanhol falado na fronteira, para que a comunicação, o ensino e aprendizado se tornem mais eficientes dentro dessa região.

\section{PERCURSO METODOLÓGICO}

A presente pesquisa se apropria da abordagem de análise qualitativa, considerando-se a existência de uma dinâmica entre o mundo real e o sujeito, tendo o processo como foco principal. Segundo Chizzotti (1991, p. 78), a finalidade de uma pesquisa qualitativa é intervir em uma situação insatisfatória, mudar condições percebidas como transformáveis, onde pesquisador e pesquisados assumem, voluntariamente, uma posição reativa.

A pesquisa-ação promove a participação dos usuários do sistema escolar na busca de soluções aos seus problemas. Este processo supõe que os pesquisadores adotem uma linguagem apropriada. Os objetivos teóricos da pesquisa são constantemente reafirmados 
e afinados no contato com as situações abertas ao diálogo com os interessados, na sua linguagem popular. (THIOLLENT, 2011, p.85)

Define Thiollent (1988):

A pesquisa-ação é um tipo de investigação social com base empírica que é concebida e realizada em estreita associação com uma ação ou com a resolução de um problema coletivo no qual os pesquisadores e os participantes representativos da situação ou do problema estão envolvidos de modo cooperativo ou participativo.

Por sua vez, Fonseca (2002) precisa:

A pesquisa-ação pressupõe uma participação planejada do pesquisador na situação problemática a ser investigada. O processo de pesquisa recorre a uma metodologia sistemática, no sentido de transformar as realidades observadas, a partir da sua compreensão, conhecimento e compromisso para a ação dos elementos envolvidos na pesquisa (FONSECA, 2002, p. 34).

A pesquisa foi sendo desenvolvida pelo método indutivo, partindo da ideia de que alunos dos cursos técnicos integrados ao médio do IFRO Guajará-Mirim, mesmo estando situados em região de fronteira com a Bolívia, não demonstram interesse em relação ao idioma. Assim, analisaremos se existem implicações entre este comportamento dos alunos e o uso da variação linguística nas aulas de espanhol. Serão realizadas pesquisas bibliográficas em livros, documentos e periódicos fornecidos pela Universidad Autónoma del Beni e Palacio de la Cultura, com o objetivo de identificação de variações linguísticas da cidade de Guayaramerín.

A investigação foi realizada em todas turmas do Ensino Médio que estudam a disciplina Espanhol, no Campus do IFRO de Guajará-Mirim/RO, na fronteira BrasilBolívia. Os dados foram coletados a partir a aplicação de questionários e rodas de conversa. Os sujeitos da pesquisa são alunos das turmas dos segundos e terceiros anos do ensino médio integrado dos turnos matutino e vespertino, sendo estes alunos da disciplina de língua espanhola. Será um total de 40 (quarenta) alunos, sendo que foram 
convidados a participar pelo menos 5(cinco) alunos de cada turma - não sendo possível atingir o número de voluntários em uma turma, aluno de outra turma supriu a demanda.

Os sujeitos da pesquisa selecionados são alunos dos segundos e terceiros anos dos cursos técnicos integrados que estudam a disciplina de espanhol, pois estes já possuem vivências e experiências com o idioma ensinado em sala de aula e no contexto familiar e social.

O objeto de estudo consistiu na análise das implicações das variações linguísticas no processo ensino-aprendizagem da LEM - Espanhol, no Campus do IFRO na fronteira de Guajará Mirim/RO, na fronteira Brasil-Bolívia. Delimitamos esta pesquisa à variação geográfica, pois quando o espanhol é ensinado, sempre surge a mesma indagação: que espanhol devo ensinar aos meus alunos? Que espanhol os alunos devem aprender? Muitas vezes, sem saber a resposta para essas indagações, o docente opta pelo español estándar, que se entende no meio dos estudos de idiomas como um espanhol padrão, modelo, e que pode ser entendido em qualquer lugar onde se fala espanhol.

Os questionários foram aplicados aos alunos dos cursos técnicos do Instituto Federal de Educação, Ciência e Tecnologia - Campus de Guajará-Mirim/RO, devidamente matriculados na disciplina de LEM espanhol. A aplicação do questionário objetivou verificar a visão dos alunos em relação ao idioma e o seu nível de contato com o idioma na fronteira, pois muitos são descendentes de bolivianos.

As rodas de conversa ocorreram em dois momentos da pesquisa, para uma melhor compreensão dos dados, conforme descrição a seguir:

O primeiro momento teve como objetivo compreender as expectativas dos alunos em relação ao idioma espanhol. O segundo momento da roda de conversa ocorreu após a construção e testagem do produto educacional em desenvolvimento. Neste momento, foram coletadas as impressões dos alunos em relação às aulas realizadas utilizando variações da fronteira.

Os dados coletados foram analisados e interpretados a partir da aplicação do método de categorização e análise do discurso, observando-se as informações implícitas no discurso dos participantes por meio dos instrumentos de coleta de dados que ocorreram em todo o processo da realização do trabalho de pesquisa.

Foram planejadas duas aulas com os alunos do Ensino Médio, utilizando o material nas aulas de espanhol para testagem do produto educacional no processo de 
ensino-aprendizagem. O teste foi realizado por um dos professores de espanhol do Campus do IFRO em Guajará-Mirim. A primeira aula foi específica sobre variação linguística, na qual o professor iniciou com explicações básicas sobre a variação em questão no caso a variação diatópica (geográfica).

Após a abordagem inicial, apresentamos alguns textos e expressões coletados para os alunos e um vídeo humorístico que apresentou a variação em questão. Em seguida, foram distribuídos cartões com palavras e expressões variadas aos alunos, que divididos em grupos elaboraram textos dramáticos explorando a linguagem da fronteira para posterior apresentação para a turma.

Na segunda aula foi promovida uma competição utilizando a ferramenta Kahoot, a partir da qual os alunos revisaram as expressões utilizadas na primeira aula e conheceram novas. Após as duas aulas, aconteceu a segunda roda de conversa, com objetivo de colher impressões dos alunos após a realização das aulas.

Com os resultados em mãos podemos perceber que a utilização da variação linguística é de suma importância para o idioma falado na fronteira, e para o ensino da língua espanhola no Campus do IFRO em Guajará-Mirim e demais escolas da região, pois essa perspectiva promove não somente a valorização das culturas da região, mas também a valorização dos próprios sujeitos falantes do idioma em suas interações sociais.

\section{RESULTADOS E DISCUSSÃO}

A discussão sobre norma deixa de lado, quase sempre, um dos fenômenos mais recorrentes da história: sociedades e línguas em contato (LAGORIO, 2001, p.193). A valorização do purismo linguístico, como forma de defesa e coesão social, acaba desvalorizando as variações que também fazem parte dessa situação sociolinguística.

Quando falamos em normatização, a língua espanhola teve um complicador a mais: a questão histórica e geográfica. Isso se deve ao processo de expansão que dispersou a língua castelhana, no começo do século XVI.

Segundo afirma Lagorio (2001), no final do século XV, a língua castelhana não é uniforme, nem universal, nem mesmo dentro da península ibérica. Entretanto, a orientação política era a de que devia ocupar um lugar hegemônico, como parte de um projeto que a tornava uma língua de poder. 
Ainda hoje, depois de tantos processos históricos ocorridos no mundo hispânico, persistem os conceitos de língua estándar e estandarización, que em português pode ser substituído por padrão e padronização. De acordo com o dicionário da Real Academia Española, estándar é o que serve de modelo, norma, padrão ou referência. Essa ideia remete à ideia de que falar o espanhol estándar significa falar bem, estando adequado a um padrão considerado como “correto". Conforme afirma Ponte (2010), as variedades da língua que podem chegar a ser padrão são aquelas que são utilizadas pelos grupos que detêm o poder, seja sob o ponto de vista econômico, político ou cultural.

Na variação linguística, afirma Bagno (2008), estão organizadas as relações de poder inerentes a toda sociedade. Sendo assim, é possível afirmar que a heterogeneidade da língua é um aspecto importante da vida social.

Segundo afirma Calvet (2002), a relação entre o falante e sua língua está carregada de subjetividade, não sendo apenas um instrumento de comunicação, pois no ato linguístico estão presentes sentimentos, atitudes que são próprios do falante e da posição que ocupa no meio social.

De acordo com Bourdieu (1977 apud GNERRE, 2009, p.5), “O poder da palavra é o poder de mobilizar a autoridade acumulada pelo falante e concentrá-la num ato linguístico. Uma variedade linguística "vale" o que "valem" na sociedade os seus falantes", isto é, vale como reflexo do poder e da autoridade que eles têm nas relações econômicas e sociais.

A linguagem não é usada somente para transmitir informações, isto é, a função referencial denotativa da linguagem, mas ela possui muitas outras funções, “[...] entre estas ocupa uma posição central a função de comunicar ao ouvinte a posição que o falante ocupa de fato ou acha que ocupa na sociedade em que vive." (GNERRE, 2009, p.5).

Atualmente, a língua espanhola é um dos idiomas mais falados em todo o mundo - conservando uma aparente homogeneidade. No entanto, existem diferenças linguísticas perceptíveis neste idioma, que não atingem somente a língua falada na América, destas diferenças, possuem maior representatividade as referentes ao léxico.

A Bolívia apresenta uma forte divisão cultural dividindo o país em dois grupos distintos: Cambas e Collas. Os Collas são os habitantes da região andina ou altiplana (ocidente boliviano) e os Cambas habitantes da parte oriental da Bolívia e da qual faz 
parte o departamento de Beni, onde se localiza a cidade de Guayaramerín. Para Rivas (2011), não é possível entender o falante boliviano sem entender a diferença entre estes grupos étnicos-linguísticos, sem compreender esta distinção da identidade local que diferencia uns dos outros, mesmo pertencendo ao mesmo território nacional, para que se possa começar a compreender a complexidade linguística e suas variações que se apresentam na fronteira Brasil-Bolívia.

Os estudos sobre variação linguística, segundo Bagno (2009), têm tido empenho de especialistas da área de estudos sociolinguísticos, embora ainda muito timidamente, quando comparados a outros estudos linguísticos.

\begin{abstract}
A Sociolinguística surgiu nos Estados Unidos em meados da década de 1960, quando muitos cientistas da linguagem decidiram que não era mais possível estudar a língua sem levar em conta também a sociedade em que ela é falada. $\mathrm{O}$ estudo da variação e da mudança na perspectiva sociolinguística foi impulsionado sobretudo por William Labov (nascido em 1972), que se tornou o nome mais conhecido da área. (BAGNO, 2009, p. 28).
\end{abstract}

Os estudos sociolinguísticos são de grande importância, pois confirmam que a língua não existe de forma isolada, conforme explica Santos (2009, p. 68), a "Sociolinguística variacionista estuda a língua em uso em uma comunidade linguística".

A partir do aspecto da heterogeneidade linguística, compreendemos que cada comunidade de fala possui características linguísticas que a distingue das outras. A partir dessa concepção, podemos inferir que:

Cada variedade é resultado das peculiaridades, das experiências históricas e socioculturais do grupo que a fala: como ele se constitui, como é sua posição na estrutura socioeconômica, como ele se organiza socialmente, quais seus valores e visão de mundo, quais suas possibilidades de acesso à escola, aos meios de informação, e assim por diante. (FARACO, 2005, p.32). 
Todos estes fatores interferem no processo de construção das variedades linguística de uma comunidade de fala, o que evidencia que uma a língua recebe influência de diversos contextos distintos e está sempre em movimento, fazendo com que a homogeneidade dificilmente exista.

Vale ressaltar a importância de analisarmos qual a relação da questão identitária com o ensino de espanhol na fronteira. Conforme afirma Di Fanti |(2005, p.21), “[...] enunciar é agir, é tomar atitude diante do outro". Logo, quando falamos em identidade, ela só pode existir na relação com o outro, “[...] pois é na diferença com esse outro que conseguimos afirmar categoricamente quem supomos ser, ainda que essa afirmação seja incompleta, ilusória, provisória, contingente". (IRALA, 2010, p.177). O que nos identifica não é só o que pensamos que somos, mas, também, o que pensamos que são os outros.

Ao discutir sobre a constituição da identidade, Silva (2000, p. 75) afirma que: "Identidade e diferença estão em uma relação de estreita dependência, enquanto a identidade é simplesmente aquilo que se é, a diferença é aquilo que o outro é”. Portanto, a identidade ao mesmo tempo em que afirma o que se é, é uma negação daquilo que não se é.

O referido autor também afirma que demarcamos esse espaço entre o "nós" e os "outros" ao mesmo tempo em que afirmamos nossa identidade nos diferenciando dos "outros", funcionando assim, como um processo de classificação, onde essas classificações são sempre realizadas do pondo de vista da identidade de quem a faz. Essa classificação é, em geral, determinada pela influência das relações de poder. (SILVA, 2000, p. 75). Portanto, apresentar a variação linguística que está presente na língua espanhola, significa à apresentação do outro, de sua cultura e diversidade.

Conforme Silva (2000), através de um processo de normalização é comum que se definam identidades como parâmetros por meio das quais as outras identidades são avaliadas, passando por um processo de hierarquização. A partir daí, a identidade “normal ou padrão" passa a ser considerada uma identidade de prestígio e carregada de positividade.

De um modo geral, o modelo de ensino de uma língua se baseia em variedades de prestígio, e esse lugar de prestígio está sempre relacionado ao lugar de poder ocupado pela variedade em questão. É comum a comparação entre o espanhol falado nos países 
da América espanhola e o espanhol falado na Espanha, pois é evidente a relação de poder, de prestígio, supondo a existência de uma variedade como sendo superior a outra. Não é raro o aluno perguntar ao professor se ele vai ensinar o espanhol da Espanha ou da Bolívia, estabelecendo, intrinsicamente, um parâmetro de comparação entre o idioma falado nos dois países - ainda que o aluno não tenha ainda uma noção de variação.

De acordo com Irala (2010, p.179), “[...] o tratamento da língua como propriedade é também uma questão identitária, tanto para a compreensão do contato intercultural, quanto para o ensino de línguas estrangeiras". Segundo a autora, podemos pensar em inúmeras questões relacionadas à temática das identidades, dentre as quais cita: identidade fronteiriça; identidade profissional do professor de línguas; identidade de aluno de língua estrangeira; identidade de falante nativo de língua espanhola.

A sensibilização em torno da "identidade fronteiriça", um olhar mais atento às peculiaridades de cada região, no que tange ao ensino de línguas, é de extrema importância, pois até pouco tempo, conforme afirmou Colombo (1997, p. 67), o discurso oficial negava a existência de um espaço fronteiriço, instaurando um limite imaginário que via a fronteira em duas partes, “[...] atribuindo-lhe a cada parte uma homogeneidade com o resto do país”. Por consequência dessa visão bipartida da fronteira, a língua e o ensino eram tratados da mesma forma.

Quanto à questão da identidade docente, o fator mais marcante é a falta de domínio em relação às variantes linguísticas presentes na fronteira e que termina por vincular o ensino do espanhol a uma variação do idioma distante da praticada na região fronteiriça. Por isso, mais uma vez frisamos a importância de estudos voltados para a variação linguística da região específica onde as línguas de fronteira são ensinadas, facilitando, assim, o trabalho docente e promovendo um ensino de forma mais contextualizada.

A identidade do aluno de língua estrangeira que estuda o espanhol como segunda língua e que não valoriza o idioma, mesmo estando em uma região de fronteira e convivendo em seu cotidiano com falantes do idioma, na própria sala de aula, não valorizam e algumas vezes até desprezam a variação da fronteira em detrimento do valorizado espanhol europeu.

E, finalmente, os falantes "nativos" da língua da fronteira, que mesmo tendo o espanhol como a língua materna, assistem às aulas de espanhol como língua estrangeira, 
onde, em muitas situações não estão presentes a variação que utilizam no seu dia a dia, não sendo abordadas nas aulas, nem mesmo o seu contexto, sofrendo muitas vezes o preconceito linguístico dos colegas em sala de aula e tendo um ensino que se distancia de suas identidades de nativos de língua espanhola, assim temos que:

Diferentemente de outros idiomas falados no Brasil, tem-se tornado cada vez mais comum falantes de espanhol como língua materna estudarem essa língua como estrangeira, principalmente em função dos processos migratórios frequentes nas últimas décadas, sem falar em toda a extensão territorial fronteiriça, em que alunos hispânicos, mesmo morando em países vizinhos, optam por escolarizar-se no Brasil. (ILARA, 2010, p. 184).

Esse fator pode suscitar a ideia de que o fato de se ter alunos nativos estudando na mesma sala de aula possa facilitar a aprendizagem e despertar o interesse dos demais, sendo essa característica um fator de motivação para aprender o idioma. Além disso, também pode gerar um ambiente de disputa de poder, onde de um lado estará o professor com a sua variação de acordo com a sua formação e do outro o nativo com sua variação fronteiriça e, ainda, a visão do aluno não nativo que considera a variação do nativo inferior à variação ensinada pelo professor.

Não queremos com a proposta de valorização da variação linguística dos falantes nativos da região de fronteira, excluir outras variações, ou mesmo a variação mais comumente presente nos cursos de formação de professores e considerada padrão internacionalmente reconhecido, mas evidenciar a diversidade da língua, sua heterogeneidade e sua riqueza.

Toda língua, diferentemente do que se acreditava e do que propõem perspectivas tradicionais de análise e ensino de línguas, é na verdade "heterogênea, múltipla, variável, instável e está sempre em desconstrução e reconstrução" (BAGNO, 2012, p.36). Este já não é um problema para os professores, como afirma Bagno (2012, p.37), “[...] o verdadeiro problema é considerar que existe uma língua perfeita, correta, bemacabada e fixada em bases sólidas”. São muitos os trabalhos que tratam sobre a variação em língua materna, de maneiras diversificadas e com muitas propostas interessantes de 
aplicação de em sala de aula ${ }^{3}$, porém poucos estudos se têm em relação a variação linguística em zonas de fronteira.

No que se refere ao processo de ensino-aprendizagem de língua espanhola, os alunos brasileiros têm uma certa facilidade no início do estudo, pelo fato de esse idioma ter origem do Latim, assim como o Português. No entanto, as semelhanças entre as duas línguas não acabam com as dificuldades que existem na aprendizagem nos diversos níveis fonético-fonológico, morfossintático ou léxico-semântico, apesar do fato de os estudantes fazerem parte de uma comunidade linguística de fronteira.

Em relação ao ensino da língua espanhola, ainda são poucas as propostas de trabalho com a variação em sala de aula. Mais difícil ainda se torna quando se trata do ensino em uma região de fronteira, onde muitas vezes a variação conhecida pelo professor e a apresentada pelo livro didático são insuficientes para atribuir sentido ao ensino que é oferecido ao aluno, o qual já possui um contato prévio com o idioma embora esse contato seja muitas vezes de um forma bastante superficial.

Gnerre (2009, p. 19) afirma que “[...] os dicionários forneceram aos vocábulos aí recolhidos uma existência abstrata que os torna totalmente diferentes dos signos excluídos do inventário", mas estas palavras não fazem sentido fora da produção linguística, somente passam a existir no momento em que são utilizadas em um determinado contexto, logo entender significa compreender a palavra no contexto em que ela aparece. Os dicionários são os principais instrumentos de estandardização de uma língua e fazem com que ela seja considerada legítima, ou seja, são os dicionários que aprovam o uso de um léxico, "mas servem também a base de outras aceitações" (GNERRE, 2009, p. 19).

O conhecimento da variação linguística na fronteira permite o ensino da LE minimizando a ideia de erro inerente aos próprios estudantes, que demonstram um certo grau de preconceito em relação às variações existentes na região - tida por alguns como incorretas e por outros como um outro idioma que não o espanhol. Sendo essas variações conhecidas dos professores de línguas da fronteira, poderão traçar um paralelo semântico e esclarecer esta variação, tendo em vista que o papel da língua estrangeira é

\footnotetext{
${ }^{3}$ Dentre eles, podemos citar: Pedagogia da variação linguística, Na língua nada é por acaso, Preconceito Linguístico, variação e identidade, etc.
} 
contribuir para o desenvolvimento social do aluno, de sua cidadania e criticidade, para que possa interagir e se comunicar em situações específicas.

Embora tenhamos na cidade de Guajará-Mirim um acesso próximo ao espanhol falado pelos bolivianos na cidade de Guayaramerín, a variação da fronteira não é conhecida e utilizada em sala de aula, deixando à margem das aulas uma riqueza não apenas linguística, mas cultural da região.

A este respeito, Carmona (2006) evidenciou que “[...] os docentes, em sua maioria, não privilegiam o ensino de variantes linguísticas em suas aulas, primando pelo ensino voltado para o espanhol peninsular." A autora diz que, os motivos apresentados pelos professores para não ensinarem as variantes da língua espanhola, seria a "falta de tempo, material não adequado, etc.” Além disso, Bagno (2009), com base em estudos sobre o ensino da variação linguística, afirma que a maioria das gramáticas e dos livros didáticos de Português limita-se à utilização de exercícios mecânicos de classificação e de análise sintática de estruturas, sem a devida contextualização para uma prática real de uso, o que revela uma concepção de língua estável e homogênea, distante da realidade linguística. Essa dificuldade também é encontrada nos livros e materiais didáticos de língua espanhola.

Tratando-se de uma análise sobre variação, devemos considerar também que, conforme Labov (1978), uma análise da variação linguística não constitui uma mera descrição da gramática, e sim uma descrição da língua que vai além dos manuais de gramática. Além disso, segundo Baralo (1999, p.17), “[...] a variação linguística é essencial para o desenvolvimento da competência sociolinguística, nas quatro habilidades: falar, ouvir, ler e escrever, competência esta capacita o indivíduo a produzir e a compreender adequadamente expressões linguísticas em diferentes contextos de uso."

Esse tipo de dificuldade relacionada à estrutura dos materiais didáticos é frequente no ensino de Espanhol como Língua Estrangeira. Por esse motivo, é importante a utilização de outros materiais nas aulas, além do livro didático, valorizando os gêneros diversos, que aperfeiçoem o trabalho com as variações.

Partindo da visão de que a língua estrangeira cumpre papel fundamental na formação de cidadãos, temos como foco principal no nosso trabalho a pesquisa das variações linguísticas da língua espanhola na cidade boliviana de Guayaramerín, uma vez que muitos descendentes de bolivianos que estudam no lado brasileiro se intimidam 
diante de vocábulos ou expressões que conhecem com outra variação e outros alunos se referem aos mesmos como se falassem errado.

A apropriação da variação linguística da região pelos professores de espanhol possibilitaria uma maior interação linguística nas aulas facilitando em muito o processo ensino-aprendizagem, além de conscientizar o aluno da diversidade dos povos falantes de espanhol no âmbito das variedades linguísticas, oferecendo, assim, condições para que os estudantes compreendam as relações entre as diversas culturas - o que colabora também para a constituição da identidade.

Apesar de autores como López Morales (2006, apud GARCÍA, 2008, p,16) afirmarem que o fato de o espanhol ser hoje a segunda língua de comunicação internacional, dever-se principalmente pelo fato de ser uma língua falada por um grande número de pessoas em inúmeras partes do mundo e de ser uma língua com uma grande homogeneidade no meio de variedades, não podemos ignorar a importância da valorização das variações que podem ocorrer numa zona específica de fala espanhola, como é o caso da fronteira.

É a partir dos pontos destacados que apresentamos esta proposta de investigação na cidade de Guajará-Mirim, na fronteira Brasil-Bolívia, região com um histórico de uma diversidade linguística e cultural, que sofreu variações por suas próprias culturas e localização regional. A importância do estudo de outras línguas, além da língua materna, existe há muito tempo (BRASIL, 2000, p.25). Primeiro valorizou-se o ensino do latim e do grego e, atualmente, valoriza-se a importância do estudo das línguas estrangeiras modernas. E embora a legislação brasileira sempre tenha mencionado a necessidade de que o ensino de línguas tenha um caráter prático, essa nem sempre tem sido a realidade observada na prática.

Fatores como o reduzido número de horas reservado ao estudo das línguas estrangeiras e a carência de professores com formação linguística e pedagógica, por exemplo, foram os responsáveis pela não aplicação efetiva dos textos legais. Assim, em lugar de capacitar o aluno a falar, ler e escrever em um novo idioma, as aulas de Línguas Estrangeiras Modernas nas escolas de nível médio, acabaram por assumir uma feição monótona e repetitiva que, muitas vezes, chega a desmotivar professores e alunos, ao 
mesmo tempo em que deixa de valorizar conteúdos relevantes à formação educacional dos estudantes. (BRASIL, 2000, p.25).

De acordo com os Parâmetros Curriculares Nacionais do Ensino Médio PCNEM, essa situação não ocorre por acaso, são inúmeras as dificuldades de se estabelecer um ensino de língua estrangeira mais prático e dinâmico. Dentre outras, pode-se mencionar a falta de profissionais para atuarem, o fato de a língua inglesa ocupar a maior parte nos currículos escolares, deixando em segundo plano o ensino de outras línguas. Isso ocorre mesmo em regiões onde o ensino de uma determinada língua seria mais interessante ao público daquela região, como nota-se em na região de fronteira. (BRASIL, 2000).

A língua estrangeira, como qualquer linguagem, tem uma importância fundamental, pois funciona como meio para se ter acesso a uma diversidade de conhecimento, levando o aluno a desenvolver, diversas formas de pensar, de criar, de sentir, de agir e de conceber a realidade, o que propicia ao indivíduo uma formação mais abrangente e, ao mesmo tempo, mais sólida. (BRASIL, 2000, p. 26).

Ao discutir sobre ensino médio no sentido da formação omnilateral, Ramos (2004) chama a atenção para as finalidades dessa etapa da educação, enfatizando o que de fato confere sentido a essa etapa da educação, destacando "sujeitos e conhecimentos". Ainda a referida autora afirma que "Sujeitos que têm uma vida, uma história e uma cultura. Conhecimentos que são construídos socialmente ao longo da história, constituindo o patrimônio da humanidade, a cujo acesso, portanto, todos têm direito." (RAMOS, 2004, p. 6).

Durante a pesquisa, o diálogo realizado com os grupos por meio das conversas desenvolveu-se entre concordâncias e discordâncias, frente aos questionamentos apresentados. Os alunos foram esclarecidos sobre o fato de que a possibilidade de enfatizar-se o ensino de variações linguísticas da fronteira não exclui a abordagem de outras variações, também pertinentes ao estudo do idioma. Houve consenso quanto à presença de variação linguística na fronteira de Guajará-Mirim e Guayaramerín.

A maioria dos alunos considera a aprendizagem da variação linguística utilizada na fronteira importante, destacando-se principalmente a possibilidade de ingresso no mercado de trabalho, tanto no lado brasileiro quanto no lado boliviano, onde cada vez 
mais cresce a exigência do domínio da língua espanhola para contratação nesse mercado. De 40 estudantes entrevistados e participantes das rodas de conversa, apenas 6(seis) estudantes consideraram que as variações peninsulares são mais importantes, pois possibilitariam a abertura para oportunidades na Europa. Não foi avaliada a situação socioeconômica dos alunos, porém pela análise das falas dos participantes, depreende-se que os que valorizam a variação peninsular em detrimento de variações locais, possuem maior poder aquisitivo e portanto pretensões mais ousadas em relação aos demais.

Quando falaram sobre a possibilidade de se comunicar em espanhol quando em contato com bolivianos, a maioria afirmou que mesmo tendo conhecimento sobre o idioma prefere falar em português e não em espanhol, indagados sobre o motivo, revelaram que ao iniciar a conversação em espanhol, os bolivianos começam a falar palavras desconhecidas por eles o que dificulta a conversação. Dos 40(quarenta) participantes 4(quatro) alunos atualmente residem na cidade boliviana e confirmam que se comunicam em espanhol quando em contato com bolivianos. Mas, surgiram durante as rodas de conversas a utilização de forma pejorativa dos termos cambas e colas. ${ }^{4}$

A utilização desses termos, próprios para designar os povos habitantes das regiões bolivianas, revela um fato social que nos leva à conclusão de que muitos dos alunos não gostam de ser identificados como pertencentes aos povos bolivianos. Portanto, o traço étnico em questão acaba recebendo um sentido negativo.

Após a aplicação das aulas de espanhol, com a utilização das variações linguísticas coletadas

em material bibliográfico, nas respostas aos questionários e na fala dos participantes, foi realizada a segunda roda de conversa, agora para coleta de impressões após as aulas com usos de variações. Os participantes consideraram interessante a aplicação das aulas, e afirmaram já haver escutado algumas das palavras e expressões utilizadas, inclusive sendo utilizadas por familiares bolivianos. Dentre esses casos, escutamos de um dos estudantes "minha avó vive falando isso". Nesse sentido, os participantes demonstraram sentimento maior de pertença à comunidade de fronteira após as aulas, e a própria participação na pesquisa envolvendo a língua espanhola, demonstrou ter despertado nesses estudantes um fortalecimento de sua identidade.

\footnotetext{
${ }^{4}$ A origem do termo é cambado, de gentílico. Hoje é utilizado para designar os povos das regiões baixas da Bolívia.
} 


\section{CONSIDERAÇÕES FINAIS}

Com o desenvolvimento da pesquisa, verificamos que existem estreitas relações de contato dos sujeitos da pesquisa com a cidade fronteiriça de Guayaramerín. Mesmo os alunos que não são descendentes de bolivianos, confirmaram, em sua maioria, relações de parentesco ou de trabalho com bolivianos. Essas informações foram obtidas por meio da resposta de 40 questionários aplicados e duas rodas de conversas.

Durante as rodas de conversa os alunos confirmaram possuir conhecimentos prévios sobre a variação linguística falada na cidade boliviana.

Um fator que causou surpresa neste primeiro momento da pesquisa foi a quantidade de alunos sensibilizados em participar e dar sua contribuição. Mesmo após a quantidade de participantes já estar completa, muitos alunos se dispuseram a participar do projeto, expondo suas relações com a fronteira e afirmando que teriam muito a contribuir.

Durante as rodas de conversas algumas questões não programadas no roteiro, mas pertinentes foram suscitadas, como por exemplo, um Campus de fronteira não possuir uma placa de boas-vindas na língua vizinha ou mesmo placas indicativas no Campus.

Após a coleta de dados, é possível avaliar que, sem dúvida, o estudo das variações da língua espanhola na fronteira tem muito a contribuir para o fortalecimento da proposta de formação humana no contexto da Educação Profissional na cidade de Guajará-Mirim, pois possibilita não apenas o estudo da língua de forma estrita, mas a língua como elemento intercultural da região buscando estabelecer relações de respeito, cooperação e aceitação das diferentes culturas que fazem parte da região amazônica.

Deve-se pensar, pois, no atendimento às diversidades, aos interesses locais e às necessidades de desenvolvimento para o mundo do trabalho global, acesso ao conteúdo científico, mas também na perspectiva local dos alunos. Portanto, no ensino da língua estrangeira, é fundamental atentar para a realidade das suas funções, no compromisso para com a formação integral do aluno. Daí não poder ser ignorado o contexto regional onde as aulas são ministradas. Com isso, torna-se possível o desenvolvimento do indivíduo em todas as suas potencialidades, o ensino da língua estrangeira deve ter o seu lugar de importância nesse processo dentro do ensino médio integrado. 


\section{AGRADECIMENTOS}

REGISTRE-SE NOSSOS AGRADECIMENTOS AO INSTITUTO FEDERAL DE EDUCAÇÃO, CIÊNCIA E TECNOLOGIA DE RONDÔNIA PELO APOIO NO DESENVOLVIMENTO DA PESQUISA, DADA SELEÇÃO OCORRIDA ATRAVÉS DO EDITAL No 04/2019 - INSTITUCIONALIZAÇÃO DE PROJETOS DE PESQUISA.

\section{REFERÊNCIAS}

BAGNO, Marcos. Nada na língua é por acaso: por uma pedagogia da variação linguística. São Paulo: Parábola, 2007.

BAGNO, M. Preconceito linguístico: o que é, como se faz. Edições Loyola, 1999.

BARALO, Marta. La adquisición del español como lengua extranjera. Madrid: Arco/Libros, 1999.

BRASIL. MINISTÉRIO DA EDUCAÇÃO. MEC - MECT (2010): Escolas de Fronteiras. Disponível em http://portal.mec.gov.br/seb/arquivos/pdf/Escolafronteiras/doc_final.pdf. Acesso em 02 fev 2019.

CALVET, Louis-Jean Calvet. Sociolinguística: uma introdução crítica. São Paulo: Parábola Editorial, 2002.

CHIZZOTTI, Antonio. Pesquisa em ciência humanas e Sociais. São Paulo: Cortez,1998.

CIAVATTA, M.; FRIGOTTO, G.; A. RAMOS, M. (orgs). Ensino Médio Integrado: concepções e contradições. São. Paulo: Cortez, 2005. 
DI FANTI, M.G. Tessitura plurivocal do trabalho: efeitos monológicos e dialógicos em tensão. Alfa. São Paulo, nº 49(2), p.19-40, 2005).

FERNÁNDEZ, Francisco Moreno. Las variedades de la lengua española y su enseñanza. Madrid: Arco Libros, 2010.

FERNÁNDEZ, Francisco Moreno. Aportes de la sociolinguística a la enseñanza de lenguas. In: Revista de Estudios de Adquisición de la Lengua Española - Reale. N. 11. Alcalá de Henares, Departamenento de Filología - Servicio de Publicaciones, 1994. P. 107135 .

GNERRE, Maurizio. Linguagem, escrita e poder. São Paulo: Martins fontes, 2009.

HALL, Stuart. A Identidade Cultural na Pós-Modernidade. Rio de Janeiro: DP\&A Editora, 2006.

IRALA, V. B. A construção do imaginário do professor em formação sobre sua aprendizagem de espanhol como língua estrangeira. In: ERNST-PEREIRA, A.; MUTTI, R. (orgs.). Práticas discursivas. Pelotas: Educat, 2008.

LABOV, Willian. Padrões sociolinguísticos. Trad. Marcos Bagno, Maria Marta Pereira Scherre, Caroline Rodrigues Cardoso. São Paulo: Parábola, 2008.

MOURA, D. O tratamento das variantes padrão e não-padrão na sala de aula. In: Denilda Moura (org) Leitura e escrita: a competência comunicativa. Maceió: EDUFAL, 2007.

PONTE, Andrea Silva. A variação linguística na sala de aula. In: BARROS, Cristiano Silva de; COSTA, Elzimar Goettenauer de Marins (coord.). Espanhol: Ensino Médio. Brasília: MEC, 2010. v. 16, cap. 8, p. 157-174.

RAMOS, Marise. Concepção do ensino médio integrado. Mossoró: Secretaria de Educação do Estado do Rio Grande do Norte, 2007. 
RIVAS, Verônica Elizabeth. Yo no soy boliviano soy carioco - Entre línguas e preconceitos na fronteira Brasil-Bolívia.

SANTOS, Renata Lívia de Araújo. A metodologia da pesquisa em sociolinguística variacionista. Revista Espaço Acadêmico, [S. l.], ano 2009, n. 97, p. 68-70, 2009.

SILVA, Tomaz Tadeo. Identidade e diferença: A perspectiva dos estudos culturais. Rio de Janeiro: Vozes, 2000.

TARALLO, Fernando. A pesquisa sociolinguística. 7.ed. São Paulo: Ática, 2004.

THIOLLENT, M. Metodologia da pesquisa-ação. São Paulo: Cortez, 2008. Metodologia da pesquisa-ação. São Paulo: Cortez, 2011. 